\title{
Asset Prices and the Measurement of Wealth and Saving*
}

\author{
Michael Reiter, Universitat Pompeu Fabra, Barcelona
}

September 1999

JEL classification: C43, E22, E44

Keywords: Real wealth, real saving, welfare, index numbers

\begin{abstract}
The paper defines concepts of real wealth and saving which take into account the intertemporal index number problem that results from changing interest rates. Unlike conventional measures of real wealth, which are based on the market value of assets and ignore the index number problem, the new measure correctly reflects the changes in the welfare of households over time. An empirically operational approximation to the theoretical measure is provided and applied to US data. A major empirical finding is that US real financial wealth increased strongly in the 1980s, much more than is revealed by the market value of assets.
\end{abstract}

Michael Reiter

Department of Economics

Universitat Pompeu Fabra

Ramon Trias Fargas 25-27

E-08005 Barcelona

Spain

e-mail: reiter@upf.es

${ }^{*}$ I am grateful to Claude Hillinger, Hans-Werner Sinn, seminar participants in Munich, Barcelona and Princeton and in particular to David Bradford for many helpful comments and discussions. 


\section{Introduction}

Developed economies spend considerable resources on the measurement of aggregate consumption, production and wealth. These data serve both as indicators of welfare and as input into explanatory macroeconomic models. With respect to the measurement of inflation and real GDP growth, economists and statistical agencies become more and more aware of the difficult index number problems involved, and try to find solutions based on economic theory. A good example is the recent discussion on the measurement of the CPI (cf. the Symposium in the Winter 1998 issue of the Journal of Economic Perspectives). At the moment, no similar efforts are made on the measurement of real wealth. Since wealth is used to buy consumption goods at different points in time, changes in the relative price of current and future consumption, i.e., changes in real interest rates, pose an index number problem in the intertemporal dimension which is similar to static index number problems.

Current practice is to compute "real wealth" as the nominal value of assets, divided by the GDP deflator, which is the price level of current goods. This procedure ignores the intertemporal index number problem altogether. It amounts to deflating the nominal value of assets by the price of one particular class of goods, namely current consumption or production. Formally, this is analogous to defining real GDP as nominal GDP divided by the price of one particular good, for example the price of hamburgers, which gives a measure that could be called the "Big-Mac-Index" of GDP.

Economists seem to be convinced that there exist better measures of real GDP than the Big-Mac-Index. In this paper I argue that the same is true for real wealth, and I develop a measure that accounts for the intertemporal index number problem. I will show, both in theory and in an empirical application, that the new measure can

significantly deviate from conventional wealth series. Such an improved measure of real wealth is important in several respects. First, it is a better welfare indicator. If the market value of assets increases because interest rates have fallen, are households richer, not just in a nominal, but in a real sense? Real wealth as I define it answers this question. It has the property that an increase in its value indicates an improvement in the economic situation of a household. I will show that this is not true for the currently used wealth measures. 
Second, real wealth plays an important role in the measurement of saving. Several authors have pointed out that conventional measures of national saving, based on the National Accounts, are insufficient. They reflect investment in physical capital ${ }^{1}$ only, and even here they are incomplete, since they use some more or less arbitrary accounting principles for asset valuation, and exclude changes in the value of existing capital. Bradford $(1989,1990,1991)$ has forcefully argued that the change in the market value of assets is a better measure of saving than those derived from the National Accounts. The same view is expressed, e.g., in Barro (1989, p.50). One can criticise these claims on two grounds (cf. the comment of Stiglitz, 1991, on Bradford). First, one may argue that asset prices contain valuation bubbles ${ }^{2}$, and changes in asset prices thus not always reflect changes in real wealth (reasonably defined). The fact that the proposed measure of national saving is very volatile, and even negative in some years, may be interpreted as pointing in this direction. The second critique concerns the inherent index number problem, caused by changes in interest rates. The latter problem is solved if saving is defined not as the change in market values, but as the change in real wealth as defined in the present paper. On the first criticism, the present paper has nothing to say. I proceed under the strict neoclassical assumptions of rational expectations and asset valuation by fundamentals, which I consider as a useful starting point of the analysis. An interesting question, which I will analyse theoretically as well as empirically, is whether the savings measure based on real wealth is less volatile than the measure based on the market value of assets.

Third, the new measure of real wealth has potential implications for the definition of the income tax base. In many European countries, as well as in the US, the "ideal" base of income taxation is considered to be the Schanz-Haig-Simons concept of income (cf., for example, Goode, 1990, p.62). This includes the change in the market value of assets, adjusted, of course, for inflation. The appeal of this concept is not derived from formal models of optimal taxation, it is rather based on more traditional considerations of fairness and ability to pay. Tax theorists often complain that the practical implementation of the income tax does not account for inflationary

\footnotetext{
${ }^{1}$ They fail to include important investment activities such as investment in human capital, public investment, and some others (see Eisner, 1988, Eisner, 1989). They also fail to account for the depletion of natural resources (Hartwick 1990).

${ }^{2}$ Cf. the literature on the excess volatility of asset prices, for example Shiller 1981, 1989.
} 
changes in asset values. This paper shows that accounting for inflation in the usual sense is still insufficient. In addition, it is necessary to account for revaluations of assets that reflect changes in the intertemporal price structure, without changing the real wealth position of households. In the spirit of Schanz-Haig-Simons, only changes in real wealth as defined in this paper should be included in the income tax base.

Finally, real wealth plays a role in the explanation of the observed consumption behavior of households. It is clear that a model of the intertemporal allocation of consumption can be formulated and solved without any reference to real wealth, as any textbook on this issue demonstrates. The market value of assets plus the expected future path of interest rates provide the necessary information to predict the consumption path. However, the concept of real wealth helps in the interpretation of household behavior, by providing a Slutsky-type decomposition of changes in consumption into wealth and substitution effects. If the values of assets increase because interest rates have fallen, does consumption rise because of a wealth effect, a substitution effect, or both? This kind of questions can be answered by reference to a theoretically founded concept of real wealth.

The plan of the paper is as follows: Section 2 develops a definition of real wealth. To allow empirical measurements, an operational approximation to the theoretical wealth concept is developed in Section 3. Section 4 studies the relationship between asset values, real wealth and interest rates in the framework of a general equilibrium business cycle model with money. Section 5 estimates real financial wealth in the US. Section 6 concludes.

\section{Theoretical Concepts of Wealth and Saving}

\section{$2.1 \quad$ Principles}

The analysis of this paper starts from the principle, which is almost a tautology, that a theoretically satisfactory definition of wealth as a welfare measure must be tied to the utility of an economic agent. However, this principle implies that changes of wealth over time are related to changes of utility over time, and these cannot always be rigorously defined. For example, the structure of the decision problem of a household with finite time horizon is different in every period (fewer and fewer periods 
to go), so that there is no firm basis for utility comparisons over time. It therefore seems necessary to employ the theoretical idealisation of an infinitely lived agent or dynasty, which discounts future utility by a constant discount factor. Formally, we require that the decision problem of the household at time $t$ can be represented in the form

$$
\max \mathrm{E}_{t} \sum_{\tau=t}^{\infty} \beta^{(t-\tau)} u\left(c_{\tau}\right)
$$

subject to certain constraints. The optimisation problem (1) leads to a Bellman-type value function $V$ which gives the expected discounted stream of utility as a function of the state variables of the household and the economy. In this case, the household faces a decision problem of the same form in each period, and changes in $V$ can serve as a basis to measure changes in real wealth. ${ }^{3}$

The proposed measure of real wealth $\left(W^{r}\right)$ will not be defined in utility units, but in money units, by use of a positive monotone transformation $\phi$

$$
W_{t}^{r}=\phi\left(V_{t}\right)
$$

which translates the value function into a money metric utility. Real wealth expressed in monetary rather than utility terms has the advantage that it is in line with traditional measurements and that it can be more easily interpreted than the theoretical concept of utility. More importantly, we will see that changes in real wealth in monetary units can be approximately measured without knowing the exact utility function of the households, and it can be aggregated over households with different utility functions.

In the following analysis, wealth is considered to be the fundamental concept, while saving is defined as the change in real wealth:

$$
S_{t}=W_{t+1}-W_{t}
$$

\footnotetext{
${ }^{3}$ From a very fundamental point of view, one could object and say that the decision problems in different periods have the same form, but are not the same problem: the household is never given the choice between a consumption path starting today and another one starting tomorrow, so that the utilities derived from these different paths cannot be compared by the revealed preference criterion. This point was already made by Hicks $(1946$, p.177) in his famous discussion of the concept of income; he discarded the problem as exceedingly academic.
} 
This definition of saving is widespread. An alternative definition is "income minus consumption". One might use the latter relationship to base a definition of income on the definition of wealth, but I will not follow up this issue here. As a starting point of the analysis, it appears more straightforward to provide a theoretically satisfactory definition of wealth than one of income.

\subsection{Wealth as money metric utility}

The index number problem related to changing interest rates can be solved by methods that are used in static contexts to measure real income, since consumption in different periods can be treated as different goods. A theoretically consistent way to define real income is by use of the expenditure function, which can be called "Money Metric Utility" (MMU) in this context. ${ }^{4}$

The following paragraphs transfer the familiar microeconomic concepts of indirect utility function, expenditure function and MMU to a dynamic economy. We assume that a household consumes each period a vector of consumption goods $c_{t}$, which may include leisure. Nominal prices of these goods are $p_{t}^{n o m}$, and the household's endowments are denoted by $e_{t}$. A contingent consumption path $\mathcal{C}$, starting at time $t$, provides expected utility

$$
U(\mathcal{C})=\mathrm{E}_{t} \sum_{\tau=t}^{\infty} \beta^{(t-\tau)} u\left(c_{\tau}\right)
$$

Let us for the moment abstract from uncertainty, and work in a deterministic framework. Then the nominal market value of the household's assets $A_{t}^{\text {nom }}$ accumulates over time as

$$
A_{\tau+1}^{n o m}=\left(1+r_{\tau}^{n o m}\right) A_{\tau}^{n o m}-p_{\tau}^{n o m}\left(c_{\tau}-e_{\tau}\right)
$$

where $r_{t}^{n o m}$ is the nominal interest rate, and $p_{\tau}^{n o m} c_{\tau}$ etc. is an inner product of vectors. In a first step, it is useful to eliminate the effects of inflation. Assume that inflation $\pi_{t}$ has been defined as the change in the price level of consumption, in a way that will be specified later. Then the price index $P_{t}$ can be defined as accumulated inflation

\footnotetext{
${ }^{4}$ Cf., e.g., Samuelson and Swamy, 1974, p.567. This approach belongs to what Diewert (1995) calls the "economic approach to index numbers". For a discussion of GDP measurement along these lines, cf. Hillinger, 1994. Pollak, 1975, used this method to construct an intertemporal cost of living index.
} 
$P_{t}=\prod_{i=1}^{t}\left(1+\pi_{i}\right)$, with a suitable normalisation for $P_{0}$. Dividing asset values by the price level (lagged, since asset values are at beginning of period), we obtain $A_{t}=A_{t}^{\text {nom }} / P_{t-1}$, the variable that is usually called "real wealth". In the following, we will use the term "market value of assets" for $A_{t}$, not $A_{t}^{\text {nom }}$.

Defining relative prices $p_{t}=p_{t}^{\text {nom }} / P_{t}$ and the real interest rate $r_{t}=\frac{1+r_{t}^{\text {nom }}}{1+\pi_{t}}-1$, we can rewrite $(5)$ as $A_{\tau+1}=\left(1+r_{\tau}\right) A_{\tau}-p_{\tau}\left(c_{\tau}-e_{\tau}\right)$. This equation, together with the transversality condition $\lim _{\tau \rightarrow \infty} R(t, t+\tau) A_{t+\tau} \geq 0$ (where $R(t, t+\tau)=$ $\prod_{i=0}^{\tau}\left(1+r_{t+i}\right)^{-1}$ is the compound real interest factor $)$, implies the household budget constraint

$$
A_{t}+\sum_{\tau=0}^{\infty} R(t, t+\tau) p_{t+\tau} e_{t+\tau}=\sum_{\tau=0}^{\infty} R(t, t+\tau) p_{t+\tau} c_{t+\tau}
$$

As arguments of the indirect utility function we need the relative prices of all goods. They are provided by the set of current and future relative prices $p_{t}, p_{t+1}, \ldots$, which we collect into $\mathcal{P}$, and the set of compound interest factors $R(t, t+\tau)$, which we collect into $\mathcal{R}$, such that $\mathcal{P}_{\tau}=p_{t+\tau}$ and $\mathcal{R}_{\tau}=R(t, t+\tau)$. Indirect utility is then defined as

$$
\nu(\mathcal{R}, \mathcal{P}, \bar{A})=\max _{\mathcal{C}} \sum_{\tau=0}^{\infty} \beta^{-\tau} u\left(c_{\tau}\right)
$$

subject to $\bar{A}=\sum_{\tau=0}^{\infty} \mathcal{R}_{\tau} \mathcal{P}_{\tau} c_{\tau}$. It gives the level of utility which can be achieved if the value of assets, including the value of endowments, is equal to $\bar{A}$. Note that the indirect utility function is defined for an individual who takes prices as given, so that the prices and interest rates are independent of the level of assets $A$. As in the static framework, we can now define the expenditure function as

$$
e(\mathcal{R}, \mathcal{P}, U)=\min A \quad \text { s.t. } \quad \nu(\mathcal{R}, \mathcal{P}, A) \geq U
$$

Provided continuity of $\nu$, the expenditure function is just the inverse of the indirect utility function w.r.t. its last argument.

Next we define money metric utility, which is based on a reference price system. In principle, one can take any set of prices as a reference, but the analysis is more relevant if we can identify a natural candidate for a price system, such that the actual prices in the economy are never very far away from it. Along the intertemporal dimension, such a natural reference price system can be given, because interest rates tend to 
be stationary variables, which gravitate about a steady state value (we will always assume the existence of a steady state). In the static dimension, this is much more problematic, and it certainly depends on the level of disaggregation of consumption. Since the topic of this paper is the intertemporal index number problem, we will not delve into this problem here, but assume that there is a steady state of the economy with constant real interest rate $r^{*}$ and prices $p_{t}^{\text {nom }}$ growing proportionally. Inflation may vary over time, but the vector of relative prices $p_{t}$ will be constant in a steady state, and can therefore be denoted by $p^{*}$. We denote the constant real interest and price paths prevailing in the steady state as $\mathcal{R}^{*}$ and $\mathcal{P}^{*}$. The money metric utility of a consumption path $\mathcal{C}$, evaluated at steady state prices and interest rates, is then given by

$$
\operatorname{MMU}\left(\mathcal{R}^{*}, \mathcal{P}^{*}, \mathcal{C}\right)=e\left(\mathcal{R}^{*}, \mathcal{P}^{*}, U(\mathcal{C})\right)
$$

We can now define real wealth, which could also be called Money Metric Indirect Utility function, as

$$
W^{r}(\mathcal{R}, \mathcal{P}, A)=e\left(\mathcal{R}^{*}, \mathcal{P}^{*}, \nu(\mathcal{R}, \mathcal{P}, A)\right)
$$

The level of real wealth related to the market value of assets $A$ (including the value of future endowments) at given interest rate and price profiles $(\mathcal{R}, \mathcal{P})$ is defined as the value of assets that would be necessary to realize the actually obtained utility level if interest rates and prices were at their steady state values. The transformation $\phi$ in Equ. (2) is therefore given by $\phi(V)=e\left(\mathcal{R}^{*}, \mathcal{P}^{*}, V\right)$.

Figure 1 illustrates this definition within a two-period model. We compare two different situations. In the first situation, the household faces the budget constraint represented by the line $A A^{\prime}$, choosing consumption bundle $E$, in the second situation the budget constraint is $A A^{\prime \prime}$ and it chooses $G$. While $G$ is on a higher indifference curve than $E$, the example was constructed so that in both situations wealth in current consumption (here $c_{1}$ ) is given by the distance $O A$. If our base price vector is represented by the slope of $A A^{\prime}$, however, real wealth in the second situations is given by $O B$, where the line $B B^{\prime}$ has the same slope as $A A^{\prime}$ and is tangent to the higher indifference curve. 


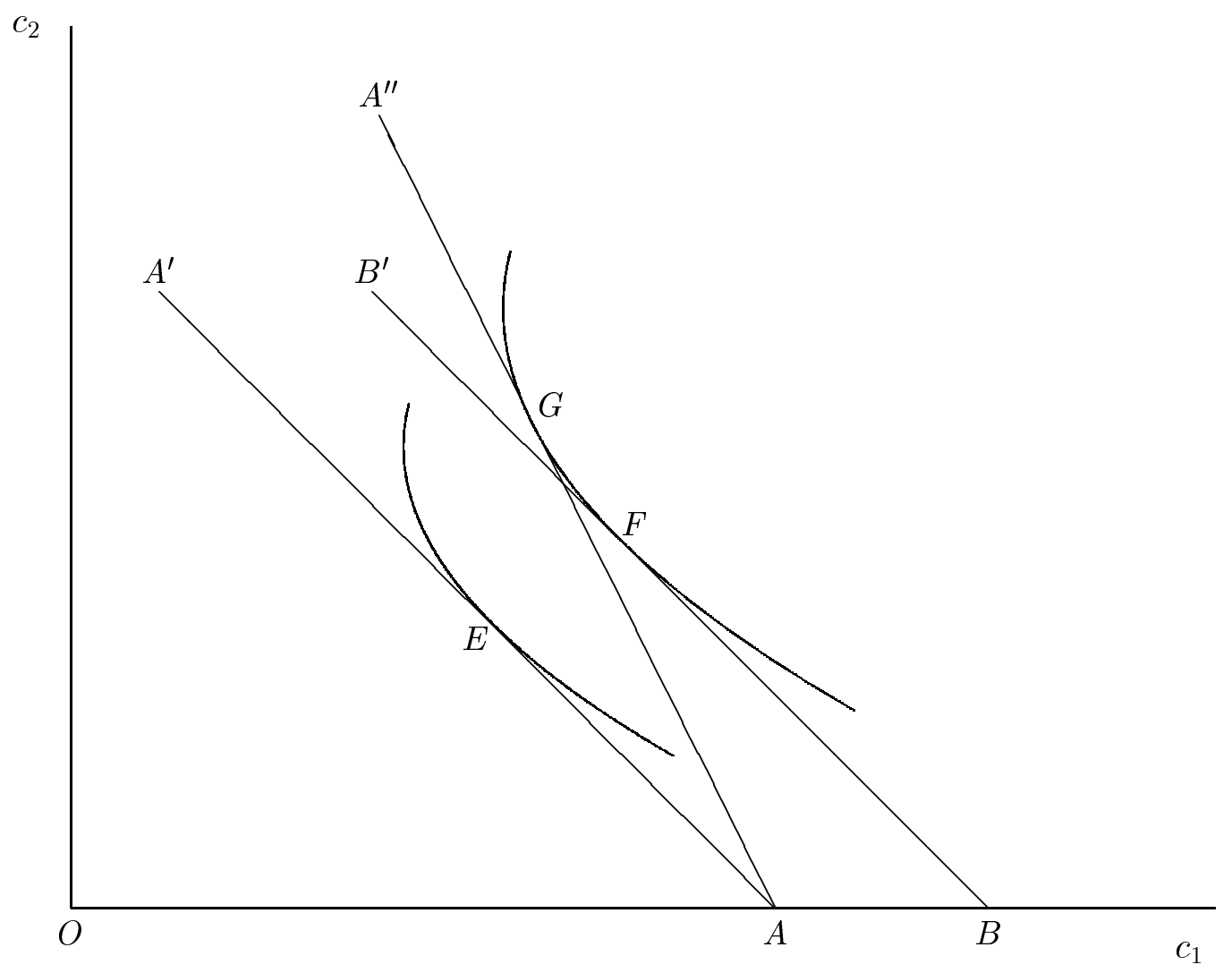

Figure 1: Illustration of real wealth in two-period model

\subsection{Stochastic economies}

In the deterministic case, goods are indexed by date. In a stochastic economy, goods are referenced not only by date, but also by state of nature, so that $c(\tau, S)$ means "Consumption in period $\tau$, if the world is in state $S$ ". If the utility is stateindependent, the exact nature of these states is irrelevant, only their probability distribution matters. We will assume that the state of nature $S_{t}$ is an element of a time-invariant state space, and denote by $\mathcal{S}$ a sequence of states $S_{0}, S_{1}$, etc.

Since interest rates $r_{t}$ and prices $p_{t}$ are functions of the state of the economy $S_{t}$, indirect utility can now be written as a function of the probability distribution $\Pi(\mathcal{S})$ over the sequence of states $\mathcal{S}$. Analogously to Equ. (7), we define

$$
\nu(\Pi, \bar{A})=\max _{\mathcal{C}} \mathrm{E}_{\Pi} \sum_{\tau=0}^{\infty} \beta^{-\tau} u(c(\tau))
$$

subject to $\bar{A}=\sum_{\tau=0}^{\infty} \int R(0, \tau, \mathcal{S}) p\left(S_{\tau}\right) c\left(S_{\tau}\right) d \Pi(\mathcal{S})$. Here, $\mathrm{E}_{\Pi}$ denotes expectation w.r.t. the probability $\Pi$, and $R(0, \tau, \mathcal{S})$ is the state-contingent interest factor (Arrow- 
Debreu price of consumption at time $\tau$ with state sequence $\mathcal{S}$ ). The expenditure function is again given by

$$
e(\Pi, U)=\min A \quad \text { s.t. } \quad \nu(\Pi, A) \geq U
$$

To define real wealth, we have to choose a reference probability distribution $\Pi^{*}$. In the discussion of the deterministic case, I have stressed that the base price system is not arbitrary, but conforms to a steady state to which the economy converges. The same can be achieved in the stochastic case if the economy under consideration is stationary and Markovian. Then we can define $\Pi^{*}(\mathcal{S})$ as the probability distribution of $\mathcal{S}$ conditional on $S_{0}=\mathrm{E}\left(S_{t}\right)$, i.e., the economy starts from its average value $\mathrm{E}\left(S_{t}\right)$. Stationarity implies that the expectation is independent of $t$.

Equipped with a reference system, we can give a definition of real wealth analogous to Equ. (8):

$$
W^{r}(\Pi, A)=e\left(\Pi^{*}, \nu(\Pi, A)\right)
$$

The situation is slightly more complicated if the economy is nonstationary, for example if $S$ contains some variables with trend. We then have to transform the state space so that it only contains stationary variables, for example by dividing all variables by an index of technical progress. This procedure is widely used in the analysis of growth models. If the economy has a stable steady state, it is always possible (one can say, by definition) to find a transformation of the state space so that relative prices and real interest rates are a function of the state variables, and the economy converges to a stationary distribution over the transformed state variables.

\section{Approximate Wealth Measures}

While the definition of real wealth is analogous to the definition of real income in a static context, the practical measurement is much more problematic because the concept of wealth refers to future paths of consumption and prices, which are of course not all observed. For practical applications, it is necessary to develop an approximation to the exact theoretical measure of real wealth such that it can be estimated with available data. This section provides approximations that are similar 
to the Laspeyre indices often used to handle static index number problems. Section 3.1 deals with the simplest case of an individual household in a deterministic environment. Sections 3.2-3.4 then provide three extensions which are necessary for the empirical measurement of national wealth in Section 5: uncertainty, aggregation over heterogenous households, and the effect of capital taxes.

\subsection{Deterministic environment}

The index developed in this section provides a linear approximation to changes in real wealth, which only requires the following information: the market value of assets; the real interest rates of different maturities, $R(t, t+\tau)$; the steady state interest rate $r^{*}$, and the steady state growth rate of consumption, $g^{*}$. It should be stressed that no information on the utility function of any household is required, nor the knowledge of the future consumption path of the economy, except of the steady state growth rate. The most problematic requirement is the knowledge of expected real interest rates. Section 5.2 will deal with this problem in a practical context.

Real wealth in a situation with consumption path $\mathcal{C}$ was defined as the price of $\mathcal{C}^{*}$ under $\left(\mathcal{R}^{*}, \mathcal{P}^{*}\right)$, where $\mathcal{C}^{*}$ is defined as the consumption profile which provides the same utility as $\mathcal{C}$ and is optimal under $\left(\mathcal{R}^{*}, \mathcal{P}^{*}\right)$. Since $\mathcal{C}^{*}$ is an optimal path under $\left(\mathcal{R}^{*}, \mathcal{P}^{*}\right)$, we know that it grows at the steady state growth rate $g^{*}$, so that we can write it as $c^{*}\left(1+g^{*}\right)^{\tau}$ where $c^{*}$ has yet to be found. At steady state prices, this consumption path costs

$$
W^{r}(\mathcal{R}, \mathcal{P}, A)=\frac{\left(1+r^{*}\right) p^{*} c^{*}}{r^{*}-g^{*}}
$$

which is the desired measure of real wealth. The task therefore reduces to finding $c^{*}$. That $\mathcal{C}^{*}$ provides the same utility as $\mathcal{C}$ is equivalent to saying that

$$
M M U\left(\mathcal{R}, \mathcal{P}, \mathcal{C}^{*}\right)-M M U(\mathcal{R}, \mathcal{P}, \mathcal{C})=0
$$

To obtain an approximative measure, we replace (12) by its first order approximation

$$
\begin{array}{r}
M M U\left(\mathcal{R}, \mathcal{P}, \mathcal{C}^{*}\right)-M M U(\mathcal{R}, \mathcal{P}, \mathcal{C}) \approx \sum_{\tau=0}^{\infty} \frac{\partial M M U(\mathcal{R}, \mathcal{P}, \mathcal{C})}{\partial c_{t+\tau}}\left(c_{t+\tau}^{*}-c_{t+\tau}\right) \\
=\sum_{\tau=0}^{\infty} R(t, t+\tau) p_{t+\tau}\left(c^{*}\left(1+g^{*}\right)^{\tau}-c_{t+\tau}\right)
\end{array}
$$


The last equality follows from the fact that the partial derivative of MMU w.r.t. the quantity of a good is equal to the price of this good. ${ }^{5}$ Setting the rhs of Equ. (13) equal to zero, we obtain

$$
\sum_{\tau=0}^{\infty} R(t, t+\tau) p_{t+\tau} c^{*}\left(1+g^{*}\right)^{\tau}=\sum_{\tau=0}^{\infty} R(t, t+\tau) p_{t+\tau} c_{t+\tau}
$$

The lhs of Equ. (14) can be further simplified if inflation is defined as the percentage change in the price of the steady state basket of goods: $\pi_{t}=p_{t}^{n o m} c^{*} / p_{t-1}^{n o m} c^{*}$. Choosing the initialisation $P_{0}=p_{0}^{n o m} c^{*} / p^{*} c^{*}$, we get $P_{t}=p_{t}^{n o m} c^{*} / p^{*} c^{*}$. Since $p_{t}=p_{t}^{n o m} / P_{t}$, this implies that

$$
p_{t+\tau} c^{*}=p^{*} c^{*}, \quad \forall \tau
$$

The rhs of Equ. (14) is equal to the market value of total assets, since the dividends of the market portfolio (including human capital) equals the discounted value of consumption in the economy. Equ. (14) therefore simplifies to

$$
\sum_{\tau=0}^{\infty} R(t, t+\tau) p^{*} c^{*}\left(1+g^{*}\right)^{\tau}=A
$$

which can be solved for $p^{*} c^{*}$. Inserting the obtained value into (11), we finally get the approximated measure of wealth

$$
W^{a}(\mathcal{R}, \mathcal{P}, A)=\frac{\left(1+r^{*}\right)}{r^{*}-g^{*}} p^{*} c^{*}=\frac{\left(1+r^{*}\right)}{r^{*}-g^{*}} \frac{A(t)}{\sum_{\tau=0}^{\infty} R(t, t+\tau)\left(1+g^{*}\right)^{\tau}}
$$

The equation provides an approximation to real wealth by multiplying the market value of assets by the correction factor $\left(1+r^{*}\right) /\left[\left(r^{*}-g^{*}\right) \cdot \sum_{\tau=0}^{\infty} R(t, t+\tau)\left(1+g^{*}\right)^{\tau}\right]$, which can be computed from the information listed at the beginning of the section.

The crucial step of the above approximation can be described as follows: rather than finding the steady state consumption profile that yields the same utility as the

\footnotetext{
${ }^{5}$ Cf. Hillinger (1994). A brief and somewhat heuristic derivation is as follows: the household maximises $\sum_{\tau=0}^{\infty} \beta^{\tau} u\left(c_{t+\tau}\right)$ subject to $\sum_{\tau=0}^{\infty} R(t, t+\tau) p_{t+\tau} c_{t+\tau}=A$. The first order conditions imply $\beta^{\tau} \frac{\partial u}{\partial c_{t+\tau}}=\lambda R(t, t+\tau) p_{t+\tau}$, where the Lagrange multiplier $\lambda$ is the marginal utility of wealth, $\partial U / \partial A$. Duality then implies that $1 / \lambda$ is the derivative of the expenditure function w.r.t. utility, and therefore$$
\frac{\partial M M U(\mathcal{R}, \mathcal{P}, \mathcal{C})}{\partial c_{t+\tau}}=\frac{\partial e(\mathcal{R}, \mathcal{P}, U(\mathcal{C}))}{\partial c_{t+\tau}}=\frac{\partial e(\mathcal{R}, \mathcal{P}, U(\mathcal{C}))}{\partial U} \cdot \frac{\partial U}{\partial c_{t+\tau}}=\frac{1}{\lambda} \beta^{\tau} \frac{\partial u}{\partial c_{t+\tau}}=R(t, t+\tau) p_{t+\tau}
$$ 
profile actually chosen, we are content with finding the one that costs the same as the actually chosen path, under the actual price system $(\mathcal{R}, \mathcal{P})$. Figure 2 , which conforms exactly to Figure 1, gives a graphical interpretation. The ray $O O^{\prime}$ is the locus of all $c_{2}$

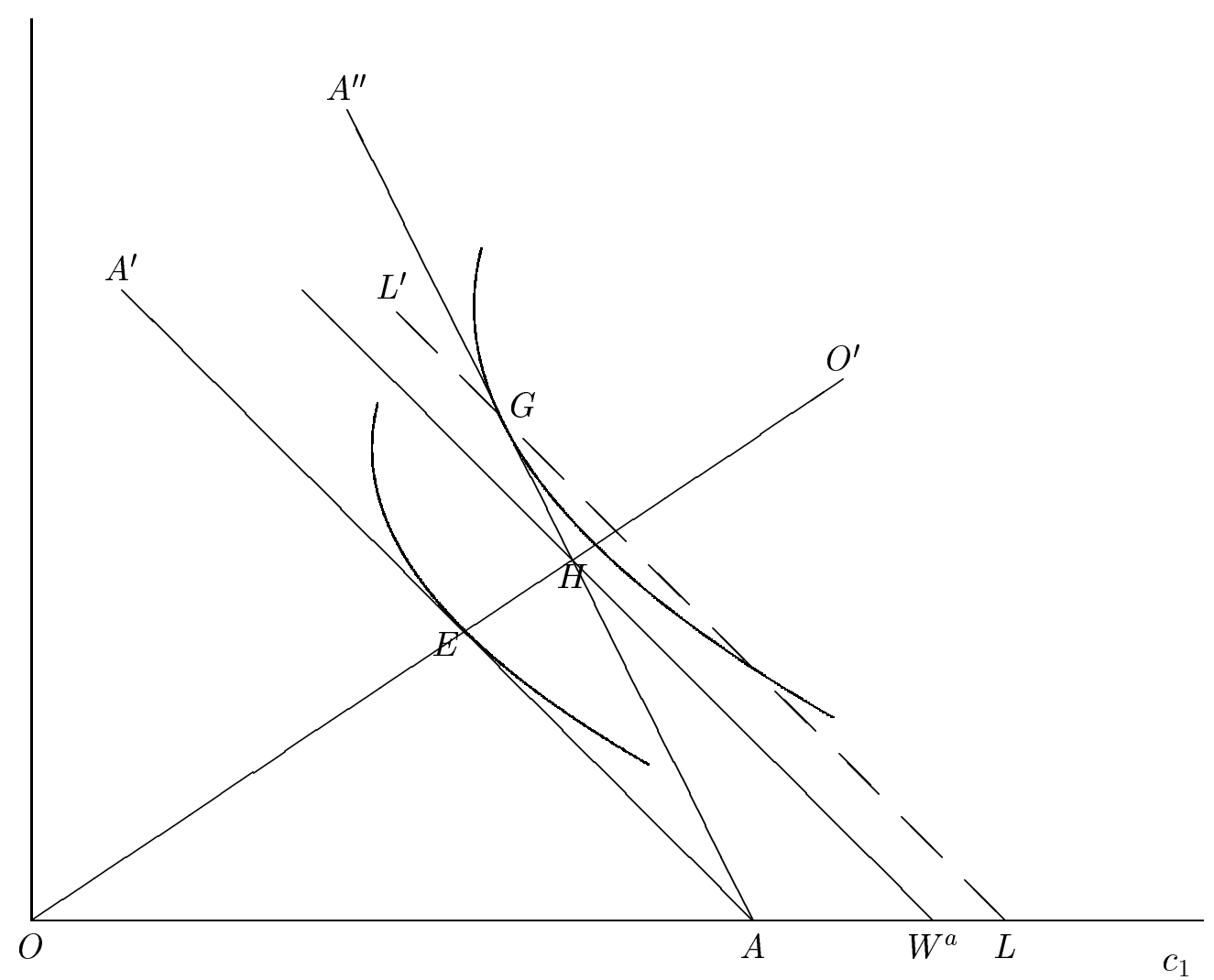

Figure 2: Illustration of approximation to real wealth

consumption bundles the household would choose with relative prices as in $A A^{\prime}$. That is, we assume homothetic preferences like with a CRRA utility function. Point $F$ of Figure 1 (which is omitted from Figure 2, together with the line $B B^{\prime}$, in order not to clutter the picture with too many lines) is the intersection of this ray with the higher indifference curve. The picture now contains two additional lines representing two different approximations to the exact real wealth (represented by $O B$ in Figure 1). One is the traditional Laspeyre approximation, given by the line $L L^{\prime}$. It is the cost of the new consumption bundle $G$ at base prices. The Laspeyre index requires knowledge of the future consumption path, which we do not suppose. What we do suppose is a) knowledge of the budget line $A A^{\prime \prime}$, because $A$ is the market value of wealth and the slope is given by the real interest rate; b) knowledge of the slope 
of $O O^{\prime}$, characterised by consumption growth in steady state. The approximation described above picks the point $H$, which is the intersection of $O O^{\prime}$ and $A A^{\prime \prime}$, and computes the price of this bundle under our base price system, which is represented by the slope of $A A^{\prime}$. Approximated real wealth is therefore given by the distance $O W^{a}$. The picture suggests that

$$
W^{a}(\mathcal{R}, \mathcal{P}, A) \leq W^{r}(\mathcal{R}, \mathcal{P}, A) \leq W^{L}(R, A)
$$

It is easily seen that this is always the case. The result w.r.t $W^{L}$ follows from the usual substitution argument, and the proof for $W^{a}$ is as follows: since the bundle $H$ is on the budget line, revealed preference shows that $U(H) \leq U(G)$. Since $H$ is optimal at the base price system, we have

$$
W^{a}(\mathcal{R}, \mathcal{P}, A)=e\left(\mathcal{R}^{*}, \mathcal{P}^{*}, U(H)\right) \leq e\left(\mathcal{R}^{*}, \mathcal{P}^{*}, U(G)\right)=W^{r}(\mathcal{R}, \mathcal{P}, A)
$$

\subsection{Uncertain returns on capital}

In the stochastic case, consumption, interest rate and prices are state contingent. With the linearisation approach as in (13), we obtain the analogue to (14)

$$
\begin{aligned}
\sum_{\tau=0}^{\infty} \int R(t, t+\tau, \mathcal{S}) p\left(S_{t+\tau}\right) c^{*}\left(S_{t+\tau}\right) d \Pi(\mathcal{S}) & \\
= & \sum_{\tau=0}^{\infty} \int R(t, t+\tau, \mathcal{S}) p\left(S_{t+\tau}\right) c\left(S_{t+\tau}\right) d \Pi(\mathcal{S})=A_{t}
\end{aligned}
$$

The lhs of (18) is the market value of the consumption path $c^{*}\left(S_{t+\tau}\right)$, which starts at $S_{t}=\mathrm{E}\left(S_{t}\right)$, at actual prices. To make the measurement operational, we replace this exact valuation formula, which holds in an economy with dynamically complete markets and a full set of state-contingent interest rates $R(t, t+\tau, \mathcal{S})$, by a simpler and widely used valuation formula, which discounts expected dividends by a risk-adjusted rate of interest. Then we obtain

$$
\sum_{\tau=0}^{\infty} R^{a d j}(t, t+\tau) \mathrm{E}_{t}\left[p\left(S_{t+\tau}\right) c\left(S_{t+\tau}\right)\right]=A_{t}
$$

$R^{\text {adj }}(t, t+\tau)$ denotes the "risk-adjusted" rate of interest, which is in our context the expected return on the market portfolio. Equation (19) has the advantage that we only have to know the expected value, not the complete probability distribution of future consumption streams. 
In the reference situation, the economy starts from $S_{0}=\mathrm{E}\left(S_{t}\right)$, and the expected value of consumption will therefore grow approximately at a constant rate, so that we can write $E_{t} c^{*}\left(S_{t+\tau}\right) \approx c^{*}\left(1+g^{*}\right)^{\tau}$. Inserting this into equation (19), we obtain an equation analogous to (16), where $R(t, t+\tau)$ was replaced by $R^{a d j}(t, t+\tau)$. If we define real wealth as the cost of the price path at prices $p^{*}$ and steady state risk adjusted interest rate $r^{a d j *}$, we again obtain the formula (17).

\subsection{Aggregation}

The above analysis applies to an individual decision maker, but we are also interested in the measurement of aggregate, or national, wealth. One could always jump from the individual to the aggregate level by invoking a "representative household", but there is a more direct way to aggregate wealth which does not rely on this problematic concept.

Assume now that the economy consists of $N$ households which are indexed by $n=1, \ldots, N$. The households may differ in endowments and preferences, with the only restriction that their utility parameters must be such that, for a given constant path of interest rates, their consumption grows at the same rate. This is a necessary condition for the existence of an aggregate steady state. In this case, $r^{*}$ and $g^{*}$ are defined as above, and Equ. (11) holds for each household separately, i.e., $W_{n}^{r}(\mathcal{R}, \mathcal{P}, A)=\left(1+r^{*}\right) p^{*} c_{n}^{*} /\left(r^{*}-g^{*}\right)$, where the bundle $c_{n}^{*}$ may differ across households. If we define aggregate real wealth as the sum of individual real wealth, we obtain

$$
W^{r}=\sum_{n=1}^{N} W_{n}^{r}=\frac{\left(1+r^{*}\right)}{r^{*}-g^{*}} \sum_{n=1}^{N} p^{*} c_{n}^{*}=\frac{\left(1+r^{*}\right)}{r^{*}-g^{*}} p^{*} c^{*}
$$

because the aggregate steady state consumption bundle $c^{*}$ is the sum of the individual consumption bundles. Applying the linear approximation to each household, we obtain the analogue to (14):

$$
\sum_{\tau=0}^{\infty} R(t, t+\tau) p_{t+\tau} c_{n}^{*}\left(1+g^{*}\right)^{\tau}=\sum_{\tau=0}^{\infty} R(t, t+\tau) p_{t+\tau} c_{n, t+\tau}=A_{n}
$$

Since $\sum_{n=1}^{N} A_{n}=A$, summing (21) over all households and using Equ. (15) leads to equation (16), and we obtain formula (17) as the approximate measure of aggregate real wealth. 


\subsection{Taxation of capital income}

So far the analysis has abstracted from governments and taxes, but in the empirical application in Section 5 we cannot completely ignore the effects of capital taxation on asset values. My discussion of this issue will be very preliminary, however, and a more thorough treatment of tax considerations is left for future work.

The market value of any asset $k$ is given by

$$
A_{k}=\sum_{\tau=0}^{\infty} R^{b e f}(t, t+\tau) D_{k, t+\tau}
$$

where $R^{\text {bef }}(t, t+\tau)$ is the before tax interest factor, and $D_{k}$ denotes the before tax dividends on the asset. In the following we simplify the analysis by assuming that asset returns are taxed only through taxes on dividends. Then the market value of assets measures both the tax component and the private component of the return on capital, discounted at the before tax interest rate. The market value of all assets is then the discounted stream of total consumption, private and government. This is appropriate since we are interested in the measurement of national wealth and saving. If we define real wealth as the cost, under steady state before $\operatorname{tax}^{6}$ interest rates, of the consumption stream that grows at the steady state growth rate and costs the same as the total stream of private and government consumption, Equ. (14) and the real wealth formula (17) still apply, with $R(t, t+\tau)$ replaced by $R^{\text {bef }}(t, t+\tau)$. One should note, however, that the first order approximation (13) cannot be rigorously justified without making any further assumptions on the determination of government consumption.

Unfortunately, the above simple procedure runs into problems when the tax treatment of government bonds, relative to that of other assets, changes. Let us illustrate this by a concrete example: assume an unexpected change in tax policy which lowers the tax rate on future corporate dividends. This increases the market value of corporate equity, while the market value of government bonds and the interest rate are approximately unchanged (abstracting from the general equilibrium repercussions of

\footnotetext{
${ }^{6}$ Since the dividends are discounted at before tax rates, one might say that this measure is, in a sense, too low. Alternatively, one could define real wealth as the price of the same consumption path under steady state after tax interest rates. This would only lead to a multiplicative change of the wealth measure.
} 
the change in corporate taxes). Since the interest rate on government bonds is approximately unchanged, formula (17) interprets the increase in equity values as an increase in national wealth. This is not correct, however: what has really happened is a redistribution from the government sector to equity owners. Accounting for this kind of effect requires a thorough analysis of changes in tax code, which is beyond the scope of the present paper. In the empirical analysis, I use Equ. (17), but try to alleviate these problems by excluding some types of assets from the analysis, $\mathrm{cf}$. Section 5.1.

\section{Real wealth in a RBC model with money}

Before applying the concept of real wealth to empirical data, it is useful to study the relationship between asset prices, interest rates and real wealth in a well understood model economy. This will help us in interpreting and understanding the empirical results. In addition, it will allow us to investigate how accurately the exact wealth concept of Section 2 is measured by the linear approximation of Section 3 . We will consider a general equilibrium model that is rich enough to study the effects of changes in productivity as well as the effects of monetary policy. I have chosen the real business cycle model with a cash-in-advance constraint and nominal wage

rigidity, because I think it is the best known model with these characteristics, and it is described in all of its aspects, including the calibration and the numerical solution technique, in a widely used textbook (Cooley and Hansen 1995). The next subsection gives a brief description of the model. For details, the reader is referred to the above mentioned source.

\subsection{The Model}

The model is a real business cycle model which is driven by technology and monetary shocks. Money is valued because of a cash-in-advance constraint. To allow for non-negligible effects of monetary policy, one type of nominal rigidity is introduced: nominal wages are set one period in advance. Labor demand then determines actual labor input. An additional feature of the model, and the only point in which it differs from the model in Cooley and Hansen (1995), is that it allows for convex adjustment 
costs in capital formation. This is a small but significant change, because otherwise, sizeable changes in interest rates or revaluations of assets are not possible.

The aggregate economy is described by the following equations:

$$
\begin{aligned}
Y_{t} & =F\left(K_{t}, H_{t}, z_{t}\right)=e^{z_{t}} K_{t}^{\theta} H_{t}^{1-\theta} \\
Y_{t} & =C_{1 t}+C_{2 t}+X_{t}+\psi\left(K_{t}, K_{t+1}\right) \\
K_{t+1} & =(1-\delta) K_{t}+X_{t} \\
z_{t+1} & =\rho z_{t}+\epsilon_{t+1} \\
M_{t+1} & =e^{\mu_{t}} M_{t} \\
\mu_{t+1} & =\eta \mu_{t}+(1-\eta) \bar{\mu}+\xi_{t+1} \\
T_{t} & =M_{t+1}-M_{t}=\left(e_{t+1}^{\mu}-1\right) M_{t}
\end{aligned}
$$

Output $Y$, which is produced according to the aggregate production function (23), is split into the cash good $C_{1}$, the non-cash good $C_{2}$, gross investment $X$ and the adjustment costs of investment $\psi\left(K_{t}, K_{t+1}\right)$, which will be specified later. Equ. (25) describes capital accumulation. The technology parameter $z$ in Equ. (26) is autocorrelated with parameter $\rho$. Money supply in Equ. (27) is exogenous, and money growth is autocorrelated with parameter $\eta$ and tends to its mean value $\bar{\mu}$, as specified in Equ. (28). New money is given as a lump sum transfer $T$ to households, cf. Equ. (29).

Firms act as price takers. They face constant returns to scale adjustment costs in physical capital

$$
\psi\left(K_{t}, K_{t+1}\right)=\phi \frac{\left(K_{t+1}-K_{t}\right)^{2}}{K_{t}}
$$

With specification (30) and production function (23), firm size does not matter. Each firm distributes nominal dividends $d_{t}$ per unit of capital, given by production minus depreciation of capital, wage costs, and the total costs of investment:

$$
d_{t}=\frac{P_{t}}{K_{t}}\left[f\left(K_{t}, H_{t}\right)-\frac{w_{t}}{P_{t}} H_{t}-\delta K_{t}-\phi \frac{\left(K_{t+1}-K_{t}\right)^{2}}{K_{t}}\right]
$$

In the labor market, the nominal wage $w_{t}$ is set at the end of period $t-1$ such that the expected labor supply and demand in period $t$ are equal (cf. Cooley and Hansen, 1995, p. 207). Once the shocks of period $t$ are realized and the price level 
is known, firms determine labor input $H_{t}$ such that $\frac{w_{t}}{P_{t}}=F_{H}\left(K_{t}, H_{t}, z_{t}\right)$ and decide about investment, and households decide about consumption and assets.

The representative household solves

$$
\max \mathrm{E}_{0} \sum_{t=0}^{\infty} \beta^{t}\left[\alpha \ln c_{1 t}+(1-\alpha) \ln c_{2 t}-\gamma h_{t}\right]
$$

subject to the constraints

$$
\begin{aligned}
& P_{t}\left(c_{1 t}+c_{2 t}\right)+b_{t+1}+P_{t}^{K} k_{t+1}+m_{t+1}=w_{t} h_{t}+\left(P_{t}^{K}+d_{t}\right) k_{t} \\
&+\left(1+r_{t-1}^{n o m}\right) b_{t}+m_{t}+T_{t} \\
& P_{t} c_{1 t} \leq m_{t}+T_{t} \\
& h_{t}=\bar{h}_{t}
\end{aligned}
$$

The lower case letters $c_{1}$ etc. denote household variables in contrast to aggregate variables. The (stochastic) paths of wages $w_{t}$, the output price $P_{t}$, the price of a claim to one unit of installed capital $P_{t}^{K}$ (which differs from $P_{t}$ because of adjustment costs), interest rates $r_{t}^{n o m}$ and dividends per unit of capital $d_{t}$ are given for the household. Also exogenous for the household, but stochastic, is the number of hours worked $\bar{h}_{t}$, because of the assumption that firms' demand determines labor input. To determine the interest rate in the model, we assume that the household can hold bonds $b$ that yield in period $t$ a nominal interest rate fixed in period $t-1$. Since there is zero net supply of bonds, the interest rate in equilibrium is such as to make the demand for this bond equal to zero.

This completes the description of the model. Cooley and Hansen (1995) describe how to find the general equilibrium of this kind of economies. They also describe how to calibrate the parameters; I have adopted their values, which are $\alpha=0.84$, $\beta=0.989, \gamma=2.53, \delta=0.019, \eta=0.49, \bar{\mu}=0.015, \sigma_{e}^{2}=0.007, \sigma_{z}^{2}=0.0089$, $\rho=0.95 . \theta=0.4$. For the adjustment costs, I have chosen the value $\phi=3.5$, so that the model matches the standard deviation of quarterly expected real interest rates $^{7}$ for the time period 1960-1993, which is equal to 1.596 .

\footnotetext{
${ }^{7}$ The expected real interest rates is defined as $\log [(1+$ nominal rate on 3 months government bond) $/(1+$ expected inflation $)]$, everything at annualised rates. Data on 3 months expected inflation rate are not available and were substituted by that of 6 months horizon.
} 


\subsection{Measuring real wealth}

The cash-in-advance model is slightly more complex than the setup of Sections 2 and 3, in two respects. First, there are two market imperfections, the predetermined money wage and the cash-in-advance constraint. Our methodology is flexible enough to handle this situation: real wealth is still given by the market value of assets which would be necessary in the reference situation to achieve the same utility level.

Second, the household has two types of assets, money and bonds, which are not convertible at the beginning of the period. (In a more complicated framework, there may be many types of consumer durables with imperfect second hand markets, which pose the same problem.) We can handle this case by assigning shadow prices to inconvertible assets. Here, we express everything in values of bonds, not money. Then, 1 dollar of money is worth $\frac{\partial U}{\partial C_{1}} / \frac{\partial U}{\partial C_{2}}$ dollars of bonds, which is more than one dollar if the cash-in-advance constraint is binding. At the shadow price, the household would demand exactly the quantity of money that it holds.

A final consideration concerns the measurement of human capital, i.e., the discounted value of the household's time endowment. Rather than the value of the total endowment (24 hours a day, here normalised to 1), I measure only the value of the time that is worked in steady state, $H^{*}$, which is probably more in line with the standard concept of human wealth. ${ }^{8}$ One should note that human capital must be defined by reference to a fixed number of hours, not the actual hours worked, since otherwise the decision of the household to buy an hour of leisure would count as a reduction in wealth.

Some technical details on the wealth computations can be found in Appendix A.

\subsection{Findings}

The relationship between real wealth, market value of assets and interest rates in this model can best be understood by looking at some impulse response functions. To facilitate the interpretation, we first consider a slight variation of the parameters of the model, where the productivity shock is uncorrelated, $\rho=0$. Table 1 traces out the

\footnotetext{
${ }^{8}$ It also simplifies somewhat the computation of the approximate wealth measure since we need not account for the wage in the inflation rate, because nothing of the restricted endowment $H^{*}$ is consumed in steady state.
} 


\begin{tabular}{rrrrrrr} 
Quarter & $A$ & $W^{r}$ & $Y$ & $K$ & $C_{2}$ & $r$ \\
\hline 1 & 0.000 & 0.000 & 0.000 & 0.000 & 0.000 & 0.000 \\
2 & 0.690 & 0.015 & 1.567 & 0.000 & 0.694 & -0.651 \\
3 & 0.045 & 0.016 & 0.021 & 0.082 & 0.041 & -0.001 \\
4 & 0.044 & 0.016 & 0.020 & 0.079 & 0.039 & -0.001 \\
5 & 0.043 & 0.015 & 0.019 & 0.077 & 0.038 & -0.001 \\
6 & 0.041 & 0.015 & 0.019 & 0.075 & 0.037 & -0.001 \\
\hline
\end{tabular}

Table 1: Effects of $1 \%$ productivity shock in period 2; percentage deviation from steady state values (interest rate: percentage points); case with uncorrelated productivity shock $(\rho=0)$

response of the economy to a one percent productivity shock in this case. In period 1 , the economy is in the steady state. In period 2 , productivity $e^{z}$ is $1 \%$ higher than expected. Higher productivity leads to higher labor input, and both factors lead to an increase in output of 1.567 percent in period 2. A part of the additional output is invested. Because of the convex adjustment costs, the marginal return on investment, and therefore the real interest rate, decrease. As a consequence, the consumption of the non-cash good $C_{2}$ also increases. From period 3 on, the economy is almost back at the steady state, which reflects the well known fact that this type of model has no significant propagation mechanism. To understand the change in real wealth $W^{r}$, note that in steady state it is equal to the discounted value of current and future production $(Y-\delta K) /(1-\beta)$ plus the value of the money stock $\frac{M}{P} \frac{\alpha C_{2}}{(1-\alpha) C_{1}}$, which sums up to 68.6 quarters of production. The one percent productivity increase during one quarter increases real wealth by approximately one percent of quarterly production, which is equal to $1 / 68.6=0.015$ percent of wealth. Output increases by more than one percent, but this is due to the decrease in leisure, and does not represent an increase in total wealth. The market value of assets increases much more than real wealth, namely by 0.690 percent. This is due to the 0.651 percentage points decrease in the real interest rate in quarter 2, which implies that all future dividends are discounted by $0.651 \%$ less. Together with the increase in real wealth and the slight decrease in interest rates in future periods, this leads to the 0.690 percent change.

In interpreting changes in consumption, one might be misled by the observation 
that the consumption of the non-cash good $C_{2}$ increases by about the same percentage as asset values. The discussion above should make it clear that this is predominantly a substitution, not a wealth effect, since real wealth has almost not changed. In period 3, consumption is close to steady state value, and the period 2 value can be explained by the Euler equation $C_{2 t}=\beta\left(1+r_{t}\right) \mathrm{E}_{t} C_{2 t+1}$. The logarithmic utility function implies a substitution elasticity of -1 , so the change in consumption is of the same size as the change in the interest rate. A wealth effect on consumption would be much more persistent.

Let us now study the reaction of the economy to shocks in productivity and money growth in the benchmark model with $\rho=0.95$. The effect of a productivity shock

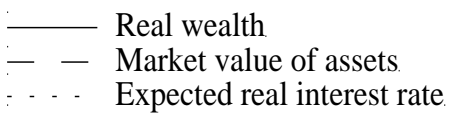

a) Productivity shock

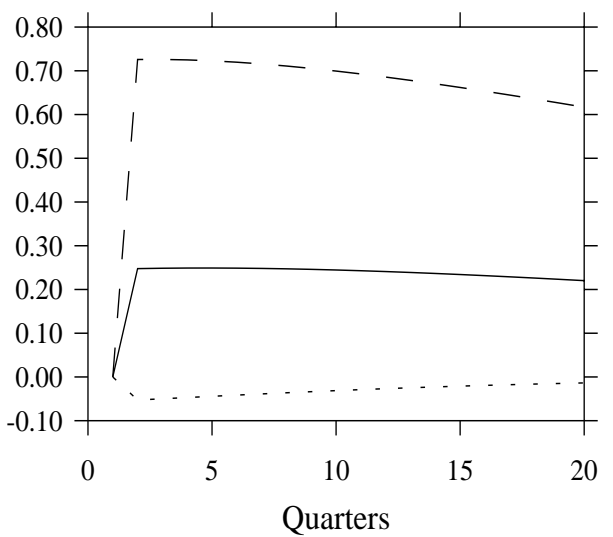

b) Monetary shock

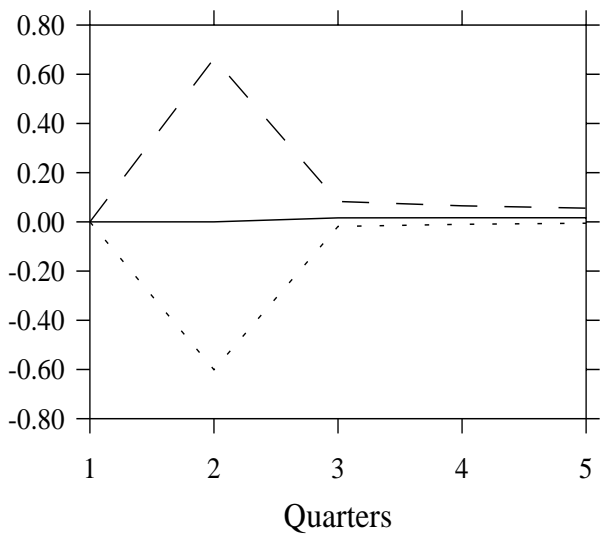

Figure 3: Impulse response functions, in percent of steady state values (interest rate: percentage points)

(Figure 3, Panel a) is qualitatively similar to the example above. Since the shock is more persistent now, there is a much bigger increase in real wealth. Since the effect on real interest rates is smaller, the difference between asset values and real wealth is less pronounced.

An unexpected increase in the money stock (Panel b) leads to a higher price level, a lower real wage rate, and higher real money balances. This increases labor demand, therefore labor input and production. Real wealth is almost unaffected: the higher 
real money balances mean an efficiency gain, while the non-optimal labor input (we are off the household labor supply curve) means an efficiency loss. Both effects are small, and the sum of the two effects is negligible. The decrease in the real interest rate due to the money shock, however, increases asset values by about 0.6 percent.

The dynamics of the model is summarised in Table 2, which provides standard deviations and cross-correlations for the most important variables. To highlight the effect of adjustment costs, the table presents results for the model with no adjustment $\operatorname{costs}(\phi=0)$ as well as those for the benchmark model $(\phi=3.5)$. The fundamental

\begin{tabular}{lrr|rrrrrr}
\multicolumn{3}{c}{ StdDev. } & \multicolumn{7}{c}{ Cross correlations } \\
& $\phi=3.5$ & $\phi=0$ & $A$ & $W^{r}$ & $W^{a}$ & $Y$ & $K$ & $r$ \\
\hline$A$ & 0.48 & 0.34 & 1.00 & 0.92 & 0.92 & 0.23 & 0.92 & -0.44 \\
$W^{r}$ & 0.06 & 0.09 & 0.38 & 1.00 & 1.00 & 0.03 & 1.00 & -0.09 \\
$W^{a}$ & 0.06 & 0.09 & 0.38 & 1.00 & 1.00 & 0.03 & 1.00 & -0.09 \\
$Y$ & 0.89 & 1.45 & 0.94 & 0.07 & 0.07 & 1.00 & 0.03 & -0.06 \\
$K$ & 0.31 & 0.47 & 0.38 & 1.00 & 1.00 & 0.07 & 1.00 & -0.09 \\
$r$ & 1.58 & 0.48 & -0.93 & -0.02 & -0.02 & -0.99 & -0.02 & 1.00 \\
\hline
\end{tabular}

Table 2: Second moments of model series; standard deviations in percent of steady state values (interest rate: percentage points); lower triangle of correlation matrix refers to benchmark case, upper triangle to case $\phi=0$.

difference between the two parametrisations is that the interest rate fluctuations are much larger with adjustment costs, 1.58 percentage points standard deviation versus 0.48 (recall that it is 1.596 for the US, 1960-1993). Adjustment costs therefore lead to higher fluctuations in asset values, while real wealth fluctuates somewhat more without adjustment costs, since the capital stock can be changed more easily. However, asset values fluctuate much more than real wealth in both parametrisations. In the benchmark case, the standard deviations differ by a factor of 8 .

The most important message from Table 2 is that changes in asset values are not a reliable indicator for changes in real wealth: the correlation between both measures is only 0.38 in the benchmark case (the change in both measures is of the same sign in $33 \%$ of cases). In contrast, the linear approximation (17), which will be used in the empirical application of the next section, is very accurate. The correlation with 
exact real wealth is close to one (more exactly, it is 0.999995 ; the sign of the change is correct in $99.5 \%$ of cases). In the case without adjustment costs, the correlation between market values and real wealth is also high (0.92); however, this is only true because the interest rate fluctuates so little that the intertemporal index number problem almost disappears.

\section{$5 \quad$ Real Wealth in the US}

This section estimates real wealth in the US from 1960 to 1993, uses the results to compute a new estimate of the US saving rate, and compares it to other, more traditional saving measures. The results will illustrate the quantitative importance of the index number considerations addressed in this paper.

The reason why I have chosen the US for the empirical application is the availability of data. The detailed balance sheets data from the Federal Reserve Board provide a good basis for real wealth calculations. Also available are historical data on interest rates on government bonds of different maturities, as well as on inflation expectations (Livingston survey data), which are necessary to compute expected real interest rates.

\subsection{Types of assets considered}

In this paper, I do not try to measure total US wealth. First, I cannot cope here with the difficulties of measuring human capital, which I therefore exclude from the analysis. Second, we have seen in Section 3.4 that our analysis may lead to misleading results if we combine assets whose relative tax treatment changes over time. I therefore exclude non-financial wealth, which consists mainly of owner occupied real estate and consumer durables, because their tax treatment differs completely from that of financial assets (Gravelle 1994, p.294). With respect to financial wealth, more accurate measurements should take into account the tax differences between equities and bonds, but this is left for future work. The estimates in Section 5 will therefore use valuation equation (17), apply it to total financial wealth, using the before tax interest rate adjusted for risk. 


\subsection{Data}

Formula (17) requires data on the market value of assets, the steady state growth and interest rates of the economy, and risk-adjusted real interest rates for different maturities. As proxy for the steady state growth rate I take average GDP growth per capita within our sample period, which is 1.88 percent per annum. As steady state interest rate I take the average expected real interest rate, defined as the nominal rate on 1 year government bonds minus the inflation rate expected for that year in previous December (taken from the Livingston Survey, cf. below), which is 2.51

percent. The data on asset values come from the Federal Reserve Board's "Balance Sheets for the US Economy 1945-1994", Table B.11.

The computation of real risk adjusted interest rates involves three steps. First we have to adjust for risk premia that longer term nominal bonds might involve. On average, the yield curve is upward sloping. I interprete the additional return on longer lived bonds as a reward for higher inflation risk. To adjust for that, I subtract from each series a constant so that the average of every interest rate series is equal to the average of the one-year rate.

Second, the interest rates must be adjusted for risk by adding a risk premium. I have made the strong assumption that the risk premium is constant over time and the same for all maturities. It is then computed as the return on financial assets minus the return on one-year government bonds. In the period 1960-1993, this is 3.42 percent. The details of the computation are in Appendix B.

The third step is the estimation of inflation expectations, for which I use the well known Livingston survey (for a discussion of the survey data, cf. Carlson, 1977). I consider survey data a much more reliable indicator of the true inflation expectations in a given historical situation than any model forecasts. A drawback of this survey is that no data on long-term expectations are available before 1991. To obtain estimates of long-run inflation expectations, I make use of the assumption that real interest rates are stationary. I therefore assume that the expectation at time $t$ of the interest rate prevailing at time $t+30$ (longest maturity available in the data) is equal to the steady state interest rate $r^{*}$. This implies that the expected inflation rate $\mathrm{E}_{t} \pi_{t+30}$ is the implicit forward nominal interest rate for $t+30$ (which can be estimated from available interest rate data) minus $r^{*}$. To obtain medium term inflation expectations, 
I assume that they regress exponentially to their asymptotic value

$$
\mathrm{E}_{t} \pi_{t+\tau}=\lambda \mathrm{E}_{t} \pi_{t+\tau-1}+(1-\lambda) \mathrm{E}_{t} \pi_{\infty}
$$

and make the simplification $\pi_{t+30}=\pi_{\infty}$ (this is not fully consistent with Equ. (32), but is a good approximation for $\lambda$ not very close to 1 , and simplifies the following estimations considerably).

The Livingston survey provides a way to obtain estimates of $\lambda$ and to test the empirical validity of the above procedure. Starting in June 1991, the survey asks for the average expected inflation rate of the next ten years. Using data until December 1998, there are 16 semiannual observations available. If we denote by $\bar{\pi}_{t, 10}=\sum_{i=1}^{10} \pi_{t+i} / 10$ the average inflation rate, Equ. (32) implies

$$
\left(\mathrm{E}_{t} \bar{\pi}_{t, 10}-\mathrm{E}_{t} \pi_{t+\infty}\right)=\beta\left(\mathrm{E}_{t} \pi_{t+1}-\mathrm{E}_{t} \pi_{t+\infty}\right)
$$

with $\beta=\left(1-\lambda^{10}\right) /(10(1-\lambda))$. Estimating the unrestricted model

$$
\left(\mathrm{E}_{t} \bar{\pi}_{t, 10}-\mathrm{E}_{t} \pi_{t+\infty}\right)=\beta_{0}+\beta_{1} \mathrm{E}_{t} \pi_{\infty}+\beta\left(\mathrm{E}_{t} \pi_{t+1}-\mathrm{E}_{t} \pi_{t+\infty}\right)+u_{t}
$$

with added error term $u_{t}$, Equ. (33) predicts $\beta_{0}=\beta_{1}=0$. OLS regression results for the sample $t=$ June 1991 until Dec. 1998 are contained in the following table:

\begin{tabular}{ccccccc} 
& $\hat{\beta}_{0}$ & $\hat{\beta}_{1}$ & $\hat{\beta}$ & $\mathrm{AR}(1)$ & $R^{2}$ & $\mathrm{DW}$ \\
\hline 1$)$ & $0.002(0.004)$ & $-0.041(0.153)$ & $0.774(0.261)$ & & 0.805 & 1.408 \\
$2)$ & & & $0.713(0.060)$ & & 0.779 & 1.530 \\
$3)$ & & & $0.718(0.087)$ & $0.207(0.300)$ & 0.760 & 1.711 \\
\hline
\end{tabular}

Standard errors in parentheses.

Regression 1 estimates the unrestricted equation (34). Both the t-statistics on $\beta_{0}$ and $\beta_{1}$ as well as the F-statistic for $\beta_{0}=\beta_{1}=0$ (not shown here) are clearly insignificant, so that the implications of the model are not rejected. Estimating the restricted model (33), Regression 2 then provides a point estimate of $\lambda$ of 0.922 , and a confidence interval from 0.961 to 0.873 . Allowing for first order autocorrelation in the error term (Regression 3) changes the results very little, and the autocorrelation parameter is not significant, so that I accept Regression 2. 


\subsection{Empirical results}

Figure 4 displays asset values and a point estimate and confidence bands for real wealth. The confidence bands result from the confidence interval for $\lambda$ in the above OLS estimation. A first observation is that real wealth is even more volatile than

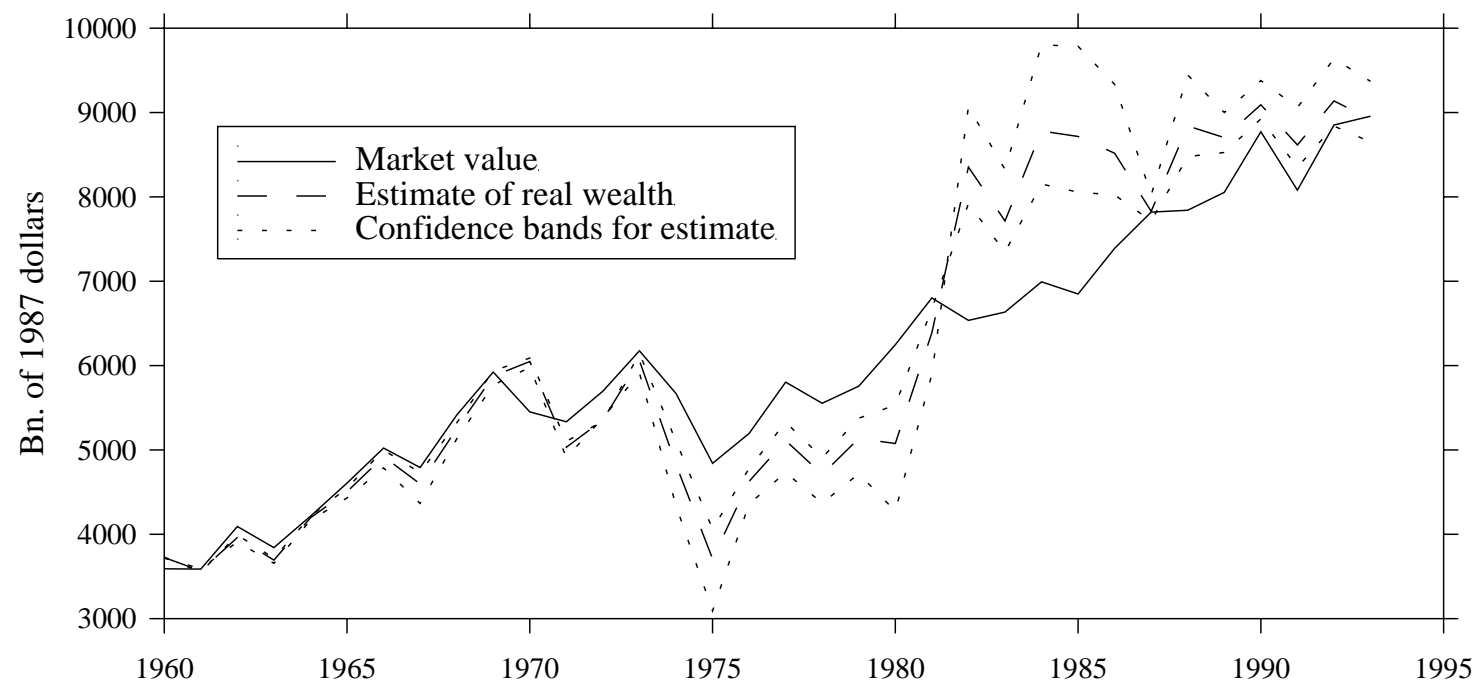

Figure 4: USA, estimates of real wealth

market values, which is in stark contrast to the predictions of the RBC model. (This result holds indeed true not only for the estimated values of $\lambda$, but for all values between 0 and 1.) The discrepancy between model and data reflects the fact that empirically, the growth in the market value of assets is slightly positively correlated with the real interest rate (correlation 0.097 in our sample; cf. Barsky, 1989 for possible explanations of this phenomenon), while it is highly negatively correlated in the model economy (-0.998 in the benchmark specification). It suggests that the RBC model does not give a realistic account of how expectations about the future growth path of the economy change over time.

While asset values climb rather continuously during the full sample, real wealth declines sharply in the mid-Seventies, and then increases enormously from 1980 to 1982. Within two years, US financial wealth increases by $65 \%$. These variations are mirrored by the movements in the real interest rate (Figure 5), which decreases in the beginning of the Seventies, and recovers in the beginning of the Eighties.

The qualitative results about the movements of real wealth appear plausible. It 


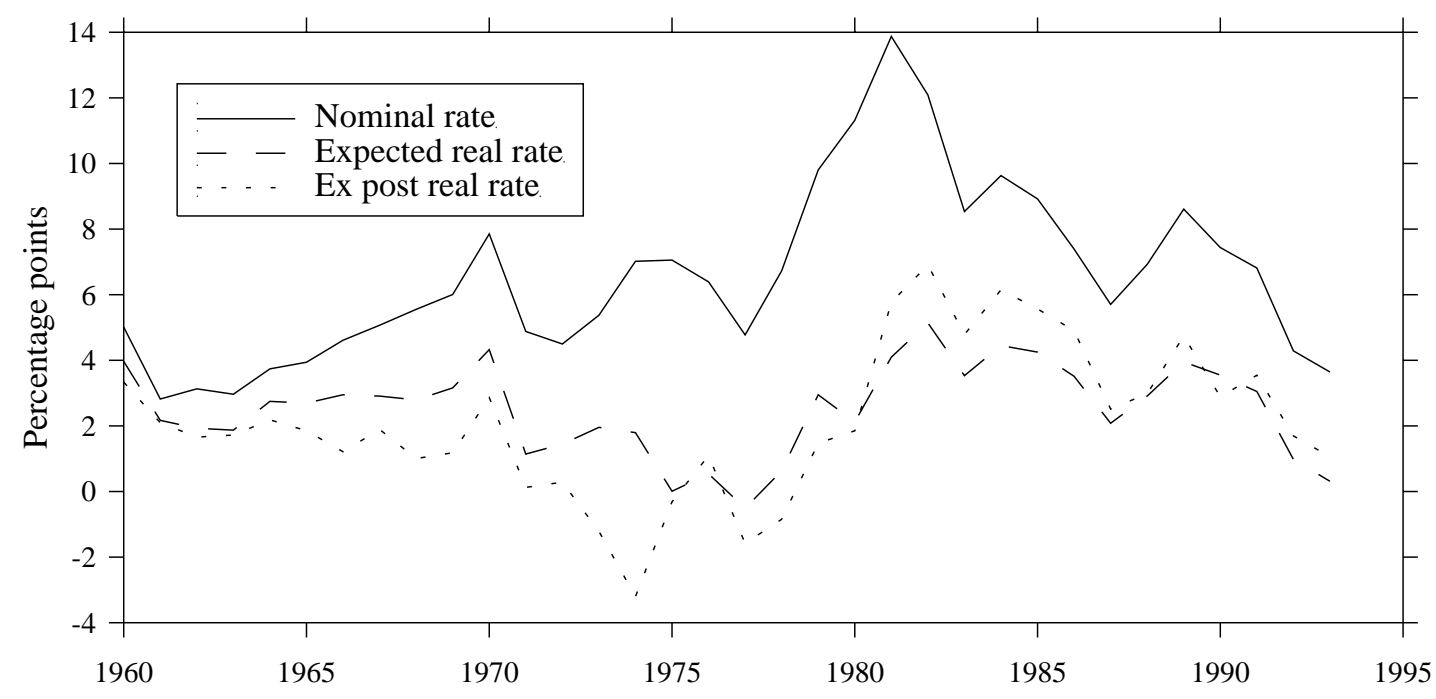

Figure 5: Interest rate on one-year US government bonds (December values; expected real rate: nominal rate minus the inflation rate expected in December for the next year; ex post real rate: nominal rate minus actual inflation rate of the next year)

is not surprising that real wealth declined significantly after the oil price shock and the recession in 1975, and the rise in asset prices at the beginning of the 1980s was justified ex post: the real rate of return on equities, measured as the dividend-price ratio plus the increase in stock values minus the inflation rate, jumped from an average of about 2 percent for the time 1960-1979 to about 11 percent in the 1980s.

Nevertheless, the size of the change from 1980 to 1982 is extreme. I see mainly two reasons why these figures may overstate the true increase in real wealth. First, the magnitude of the changes is rather sensitive to the value of $\lambda$ chosen. For the point estimate $\lambda=0.922$, the change is 65 percent. For the lower bound of the confidence interval, $\lambda=0.873$, the change is 43 percent. If one distrusts the OLS estimates and takes, for example, $\lambda=0.5$, which implies quick converge of inflation expectations to their asymptotic value, the change is only 17 percent. Second, we have not worked out the effects of the 1981 tax reform on asset values and real wealth.

Furthermore, it is not clear whether this increase in real financial wealth constitutes an increase in national wealth. Since we have excluded human wealth from our measurement, we cannot rule out that what goes on is partly a redistribution from labor to capital, possibly due to a decline of union power. More comprehensive accounts are necessary to decide these issues. 
Figure 6 translates the wealth measures into saving rates, and compares them to the traditional measure of saving based on the National Income and Product Accounts (NIPA). NIPA saving is defined as exports minus imports plus inventory accumulation plus change in tangible wealth, including consumer durables and government real assets. The other two series are the change in the market value of financial assets, and real financial wealth (point estimate), with changes in tangible assets added to both series without adjustments. Again, it is obvious that changes in asset values

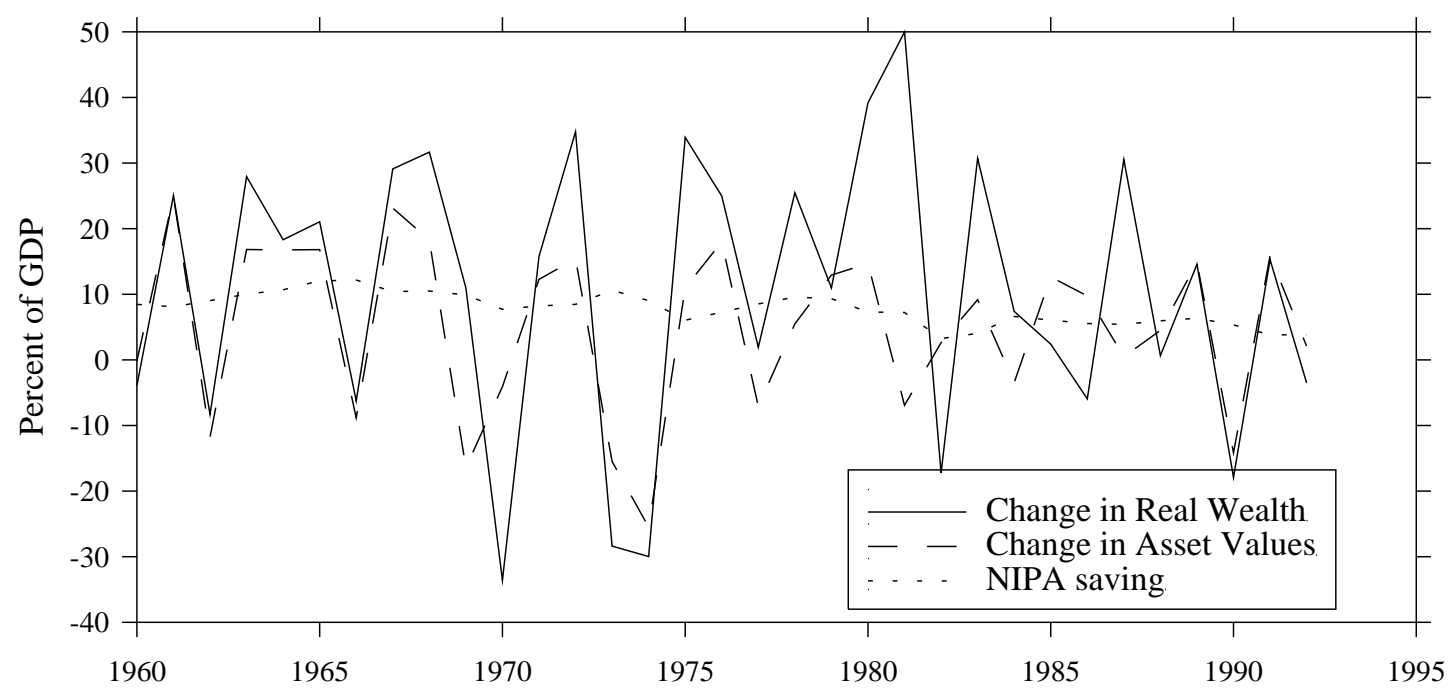

Figure 6: USA, Saving rates in percent of GDP

and real wealth fluctuate much more than the NIPA measure of saving; real wealth gives an even more volatile series of saving than asset values.

\section{Conclusions}

In an environment where real interest rates fluctuate as much as they do in our economies, the market value of assets, in terms of current consumption or GDP, is not a good measure for real wealth, in the sense that it does not correctly measure improvements in the economic situation of households. This applies to national as well as to individual wealth. The paper has developed a theoretically consistent definition of real wealth as a welfare measure. Applying this concept to postwar US data, it was shown that changes in real wealth and in market values may differ substantially. For example, the 1980s saw an enormous increase in real wealth that 
was not reflected in the market value of assets.

In interpreting these results, one should keep in mind that the empirical measurement of real wealth faces a number of problems. One problem comes from the fact that expected real interest rates are currently not readily observable. The introduction of indexed government bonds in the US and in the UK will probably allow more reliable wealth measurements in the future. Problems that await further research concern the consideration of variations in capital taxation and in risk premia. The advantage of a theoretically grounded definition of real wealth is to provide clear guidelines on how to improve and refine existing measurements. The measure proposed here is flexible enough to be applied in many different economic environments.

\section{A Computational Details in the Monetary Model}

To solve the RBC model, a linear-quadratic approximation about the steady state (Hansen and Prescott 1995) is used. The computation of interest rates is standard. The market value of total assets is computed by the following procedure. The linearquadratic approximation gives a linearised model with state vector $x_{t}$ and dynamic equation $x_{t+1}=T x_{t}+u_{t+1}$ where $T$ is the transition matrix. If $A(x)$ is the market value of an asset with dividends $D(x)$, the first order condition of the household implies

$$
U_{C_{2}}\left(x_{t}\right) A\left(x_{t}\right)=U_{C_{2}}\left(x_{t}\right) D\left(x_{t}\right)+\beta \mathrm{E}_{t}\left[U_{C_{2}}\left(x_{t+1}\right) A\left(x_{t+1}\right)\right]
$$

where $U_{C_{2}}$ is the marginal utility of the non-cash good $C_{2}$. Using the quadratic approximation

$$
U_{C_{2}}(x) D(x)=x^{\prime} Q x
$$

with a symmetric matrix $Q$, Equ. (35) implies that

$$
U_{C_{2}}(x) A(x)=p_{0}+x^{\prime} P x
$$

where the constant $p_{0}$ and the matrix $P$ satisfy

$$
\begin{aligned}
& P=Q+\beta T^{\prime} P T \\
& p_{0}=\beta \operatorname{tr}\left(\Sigma_{u} P\right) /(1-\beta)
\end{aligned}
$$


The solution to the first equation is given by $(\vec{P})=\left(I-\beta T^{\prime} \otimes T^{\prime}\right)^{-1}(\vec{Q})$. The constant $p_{0}$ is a risk premium, it depends on the variance of the shock $\Sigma_{u}$. Since the solution of the model uses an approximation that implies certainty equivalence, the computations ignored this constant for reasons of consistency, and computed asset values as

$$
A(x)=x^{\prime} P x / U_{C_{2}}(x)
$$

An approximation about the steady state $x^{*}$ was also used for the computation of "exact" real wealth. Since the utility function (31) is linear in $h$,

$$
W^{r}(x)=A\left(x^{*}\right)+\left(A(x)-A\left(x^{*}\right)\right) \frac{w\left(x^{*}\right)}{\gamma} ;
$$

provides a very good approximation.

\section{B Returns on financial wealth}

Financial wealth is defined as the sum of the financial assets of households and of the government. It excludes tangible assets of households, which mainly consist of owner-occupied real estate and of consumer durables. The income accruing to total financial assets was computed as:

\begin{tabular}{ll} 
Series & Source \\
\hline $\begin{array}{l}\text { Net interest } \\
\text { imputed net interest on owner- }\end{array}$ & NIPA Table 1.14, s. 29 Table 8.18, s. 93, 100, 105 \\
occupied housing etc. & \\
$+\quad 50 \%$ of proprietors' income & NIPA Table 1.14, s. 9 \\
$+\quad$ corporate profits & NIPA Table 1.14, s. 20 \\
$-\quad$ undistributed profits & NIPA Table 1.14, s. 32 \\
$+\quad$ capital gains on corporate equity & corporate equity (Bal. Sheets \\
& Tab. B.100) $x$ perc. change of \\
& Standard and Poor 500
\end{tabular}

Two comments on this formula are necessary. First, all returns are gross of taxes. Second, since I do not see a convincing way to split proprietors' income into a labor and a capital component, I counted 50 percent of it as capital income. This is of course only a rough guess, but it gives plausible figures: in 1990, equity in noncorporate 
business was about 2.5 trillions, proprietors' income was about 400 billions, and there were about 10 million people self-employed. The splitting used gives each selfemployed an annual income of $\$ 20,000$, and leaves an $8 \%$ return on equity. The capital component is perhaps overstated; this may serve to compensate for the fact that we do not capture capital gains on noncorporate equity. The return on financial assets is then computed as the average of capital income over financial assets.

\section{References}

Barro, R. J.: 1989, The Ricardian approach to budget deficits, Journal of Economic Perspectives 3(2), 37-54.

Barsky, R. B.: 1989, Why don't the prices of stocks and bonds move together, American Economic Review 79(5), 1132-45.

Bradford, D. F.: 1989, Market value vs. financial accounting measures of national saving, NBER Working Paper 2906.

Bradford, D. F.: 1990, What is national saving?: Alternative measures in historical and international context, NBER Working Paper 3341.

Bradford, D. F.: 1991, Market value versus financial accounting measures of national saving, in B. D. Bernheim and J. B. Shoven (eds), National Saving and Economic Performance, NBER, University of Chicago Press.

Carlson, J.: 1977, A study of price forecasts, Annals of Economic and Social Measurement 6(1), 27-56.

Cooley, T. F. and Hansen, G. D.: 1995, Money and the business cycle, in T. F. Cooley (ed.), Frontiers of Business Cycle Research, Princeton University Press, Princeton.

Diewert, E.: 1995, Axiomatic and economic approaches to elementary price indexes, NBER Working Paper 5104.

Eisner, R.: 1988, Extended accounts for national income and product, Journal of Economic Literature 26(4), 1611-84. 
Eisner, R.: 1989, The Total Incomes System of Accounts, University of Chicago Press, Chicago.

Goode, R.: 1990, Key issues in the reform of personal income taxes, in S. Cnossen and R. M. Bird (eds), The Personal Income Tax. Phoenix from the Ashes?, Elsevier, Amsterdam.

Gravelle, J. G.: 1994, The Economic Effects of Taxing Capital Income, MIT Press, Cambridge.

Hansen, G. D. and Prescott, E. C.: 1995, Recursive methods for computing equilibria of business cycle models, in T. F. Cooley (ed.), Frontiers of Business Cycle Research, Princeton University Press, Princeton.

Hartwick, J. M.: 1990, Natural resources, national accounting and economic depreciation, Journal of Public Economics 43(3), 291-304.

Hicks, J. R.: 1946, Value and Capital, 2nd edn, Clarendon Press, Oxford.

Hillinger, C.: 1994, Applied cardinal welfare economics: Conceptual foundation, empirical measurement and aggregation, Münchner Wirtschaftswissenschaftliche Beitrage 94-05.

Pollak, R. A.: 1975, The intertemporal cost of living index, Annals of Economic and Social Measurement 4(1), 179-95.

Samuelson, P. A. and Swamy, S.: 1974, Invariant economic index numbers and canonical duality: Survey and synthesis, American Economic Review 64(4), 566-93.

Shiller, R. J.: 1981, Do stock prices move too much to be justified by subsequent changes in dividends?, American Economic Review 71(3), 421-36.

Shiller, R. J.: 1989, Market volatility, MIT Press, Cambridge, Mass. and London.

Stiglitz, J. E.: 1991, Market value versus financial accounting measures of national saving: Comment, in B. D. Bernheim and J. B. Shoven (eds), National Saving and Economic Performance, NBER, University of Chicago Press. 